\title{
功能农业关键科学问题研究进展与“十四五” 发展建议
}

尹雪斌 ${ }^{1,2,3,5^{*}}$, 赵其国 ${ }^{1,3}$, 印遇龙 ${ }^{6}$, 陈清清 ${ }^{2,4}$, 王张民 ${ }^{2,3}$, 宋佳平 ${ }^{5}$, 王晓丽 ${ }^{5}$, 林锦铨 ${ }^{5}$, 王莉莉 ${ }^{7}$, 刘晓航 ${ }^{8}$, 张泽洲 ${ }^{2}$, 张宁 ${ }^{2}$

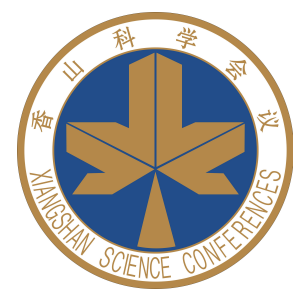

1. 中国科学技术大学苏州高等研究院, 功能农业重点实验室, 苏州 215123;

2. 国家粮食产业(功能稻米)技术创新中心, 南京 210031 ;

3. 南京恒宝田功能农业产业研究院, 南京 210031;

4. 宜春学院生命科学与资源环境学院, 宜春 336000 ;

5. 中国科学技术大学地球和空间科学学院, 合肥 230026 ;

6. 中国科学院亚热带农业生态研究所, 长沙 410125;

7. 湖南农业大学农学院, 长沙 410128;

8. 山西农业大学农学院, 太原 030801

*联系人, E-mail: xbyin@ustc.edu.cn

2021-07-01 收稿, 2021-09-26 修回, 2021-09-28 接受, 2021-09-30 网络版发表

广西科技重大专项(桂科AA17202010)、农业农村部富硒产品开发与质量控制重点实验室/富硒食品开发国家地方联合工程实验室开放课题 (Se-2019A02)和恩施土家苗族自治州科技局科技项目(D20180031)资助

摘要 功能农业是赵其国院士在2008年提出的农业新概念，主要是指农产品的营养化、功能化，旨在解决全球性 的“隐性饥饿”问题, 并重点满足消费者“吃出健康”的新需求. 香山科学会议第669次学术讨论会与会专家认为, 历经 13 年的探索, 功能农业已初步形成了独特的学科和科技创新体系, 实现了从“0”到“1”的突破. 本文扼要阐述了9个方 面关键科学问题及其相关研究进展: (1) 通过对全国及区域土壤中矿物质的时空分布特征, 反映母质和成土过程对 土壤矿物质的含量影响; (2) 土壤与作物间矿物质的吸收、转化，如人工根系实验系统(ARE系统)的建立、土壤中 矿物质生物有效性的评价方法, 以及植物中功能成分的转化机理等; (3) 矿物质和重金属密切相关的超富集植物研 究; (4) 功能农业生产中功能成分对生物和环境影响评价; (5) 功能农业长期科学试验站的研究成果; (6) 功能农产品 所制备的食物在蒸、炒、煮等烹调过程中以及其他加工技术下的功能成分形态变化的相关研究; (7) 在健康效应 评价方面, 对功能性产品对人体健康的影响及其机理, 以及相关功能农产品的千预研究; (8) 天然富硒营养强化项 目的研究; (9) 基准物质的研制情况. 在功能农业新技术研发方面, 概述了包括食品、土壤和植物等功能成分及其 形态的快速检测技术，基于功能农业种养一体化的功能畜牧业研究，涉及抗性淀粉、花青素等稻麦功能种质培育， 功能物质的精准给肥调控技术等，有关新方法、新设施、新设备的研究进展. 但目前我国功能农业总体上尚处于 发展初期, 创新链条还不完备, 科技创新体系缺少国家平台和支持系统性创新的重大项目, 与国家战略需求、地方 政府发展愿望还不匹配. 针对这些问题, 本文提出了我国“十四五”期间功能农业的发展目标, 并提供了一些发展建 议, 希望有助于推动我国功能农业实现从“1”到“100”的跨越式发展.

关键词功能农业, 隐性饥饿, 物质流, 功能成分

引用格式: 尹雪斌, 赵其国, 印遇龙, 等. 功能农业关键科学问题研究进展与“十四五”发展建议. 科学通报, 2022, 67: 497-510

Yin X B, Zhao Q G, Yin Y L, et al. The review of key scientific issues of functional agriculture and development suggestions for "14th Five-Year Plan" (in Chinese). Chin Sci Bull, 2022, 67: 497-510, doi: 10.1360/TB-2021-0383 
全球正面临食物中矿物质缺乏的“隐性饥饿”问题 以及由此导致的健康风险. 据国际锌协会(International Zinc Association)报道, 目前全球 $1 / 3$ 的人群面临矿物质 锌缺乏的问题，中国居民已经处于“中度缺锌” 状态 ${ }^{[1]}$. Jones等人 ${ }^{[1]}$ 指出, 在 100 年内, 全球大部分地区土壤硒 含量将降低, 部分地区下降幅度将达到 $10 \%$. 《20152017年中国居民能量和主要营养素的摄人情况与健康 状况》 ${ }^{[2]}$ 利用了2015 2017年中国居民营养与健康状况 监测数据, 结果表明, 中国有 $97 \%$ 的居民存在膳食钲摄 人不足的风险, $44 \%$ 的居民膳食锌摄人量达到或超过推 荐摄人量(recommended nutrient intake, RNI), 70\%的人 群膳食铁摄人量达到或超过RNI, 绝大多数居民都存在 膳食维生素 $\mathrm{A} 、 \mathrm{~B}_{1} 、 \mathrm{~B}_{2}$ 和 $\mathrm{C}$ 摄人不足的风险 ${ }^{[2]}$. 研究显 示, 美国农产品中蛋白质、钙、磷、铁、核黄素和维 生素A等功能成分含量自1950年以来的半个世纪显著 下降 ${ }^{[3]}$. 为解决这一全球性“隐性饥饿”问题, 2008年, 赵 其国院士在《中国至2050年农业科技发展路线图》 ${ }^{[4]}$ 中首次提出功能农业的概念. 过去13年，围绕“岩石-土 壤-肥料-作物/动物-食品-人体”链条中功能性物质流的 传输规律与调控技术, 众多学者开展了一系列研究和 探索. 涵盖的关键科学问题包括: 成土母质和过程对土 壤功能物质的影响、土壤-作物间功能物质的吸收转 化规律、功能农业的环境效应评估、功能农产品和食 品的加工过程功能成分的形态变化、功能物质的人体 健康效应研究以及功能农业精准调控新技术.

为总结过去 10 余年来我国功能农业的研究进展, 并梳理下一步重点攻关的科学问题、探讨未来的发展 战略, 2019年11月28 29日, 以“功能农业关键科学问题 与发展战略”为主题的香山科学会议第669次学术讨论 会在北京成功召开. 会议认为, 我国功能农业已经实现 了从“0”到“1”的突破，目前处于从“1”向“100”的跨越式 发展阶段. 本文在阐述功能农业的基本理论基础上, 重 点介绍了当前关注的功能农业关键科学问题、新技术 及其进展概要, 并结合国家乡村振兴战略、健康中国 战略等社会发展需求，探讨了我国功能农业“十四五” 的发展战略, 提出了一些发展建议.

\section{1 功能农业基本理论及其发展过程}

功能农业从提出至今经历了 4 个标志性发展阶段. （1）提出阶段. 2008年, 赵其国院士在《中国至2050年 农业科技发展路线图》 ${ }^{[4]}$ 中首次提出功能农业概念. 功 能农业被定义为: 天然富含有益成分的土壤、生境中
生长或通过生物营养强化技术及其他生物技术培育, 实现农副产品中一种或多种有益健康成分(如矿物质 和生物化合物等)基于人类健康需求作出标准化优化 的生产实践. 这些有益健康成分被称为功能成分或功 能物质. (2) 现代新型农业阶段. 赵其国院士在《科技 发展新态势与面向 2020 年的战略选择》 ${ }^{[5]}$ 中论证功能 农业是我国“十二五”、“十三五”最有希望取得突破的 农业新领域.（3）生态高值农业的支撑性技术阶段.

《生态高值农业: 理论与实践》 ${ }^{[6]}$ 又进一步明确: 功能 农业是构建生态高值农业产业体系的支撑性技术，(4) 学科体系雉形初显阶段. 2016年初, 赵其国院士、尹雪 斌博士合著了功能农业方向的首部著作一《功能农 业》 ${ }^{[7]}$, 初步阐释了功能农业的概念提出历程、科技创 新、产业发展、未来展望, 并向政府、科技界、产业 界和社会公众各界提出发展功能农业的 8 点建议. 功能 农业是继解决人们“吃饱”问题的高产农业、人们“吃 得安全”的绿色农业和有机农业之后的第3个农业发展 阶段, 旨在解决人们当前面临的必需矿物质缺乏的“隐 性饥饿”问题, 不断满足人们日益提高的“吃好”的要求.

\section{2 功能农业关键科学问题及其研究进展}

功能农业重点围绕功能物质在“岩石-土壤-肥料作物/动物-食品-人体” 链条中(图 1) 的传输规律与调控 技术, 进行正向研究与逆向设计. 一方面, 对从岩石到 人体链条中功能成分的传递过程、规律进行正向研究; 另一方面, 基于人体对功能成分的实际需求开展逆向 设计, 反推动物或农作物中的功能成分含量, 再逆向设 计功能肥料、功能饲料, 实现由土壤、饲料调控作 物、动物中功能成分含量.

我国初步建立了硒、锌等部分矿物质及元素形态 分析技术体系, 包括实现了土壤、初级农产品、食品 和动物体中的宏量、微量和超痕量元素的定量检测, 以及从小分子到大分子的形态分析技术, 尤其是硒元 素的有机形态分析技术; 开发了针对功能农业研究的 基准功能肥、基准功能食材等, 以及生物有效性评估 方法体系; 形成了矿物质从人工模拟胃肠试验和动物 试验评价方法, 到人群干预的安全性与有效性评估方 法体系; 开展了不同规模的实验, 包括进行室内盆栽培 养实验, 以及亩级、十亩级、百亩级、千亩级和万亩 级尺度上的大田试验, 推动科研成果的转化和应用. 功 能农业研究体系总体归纳为, 功能农业围绕基础研 究、方法体系、应用技术以及标准体系开展研究 


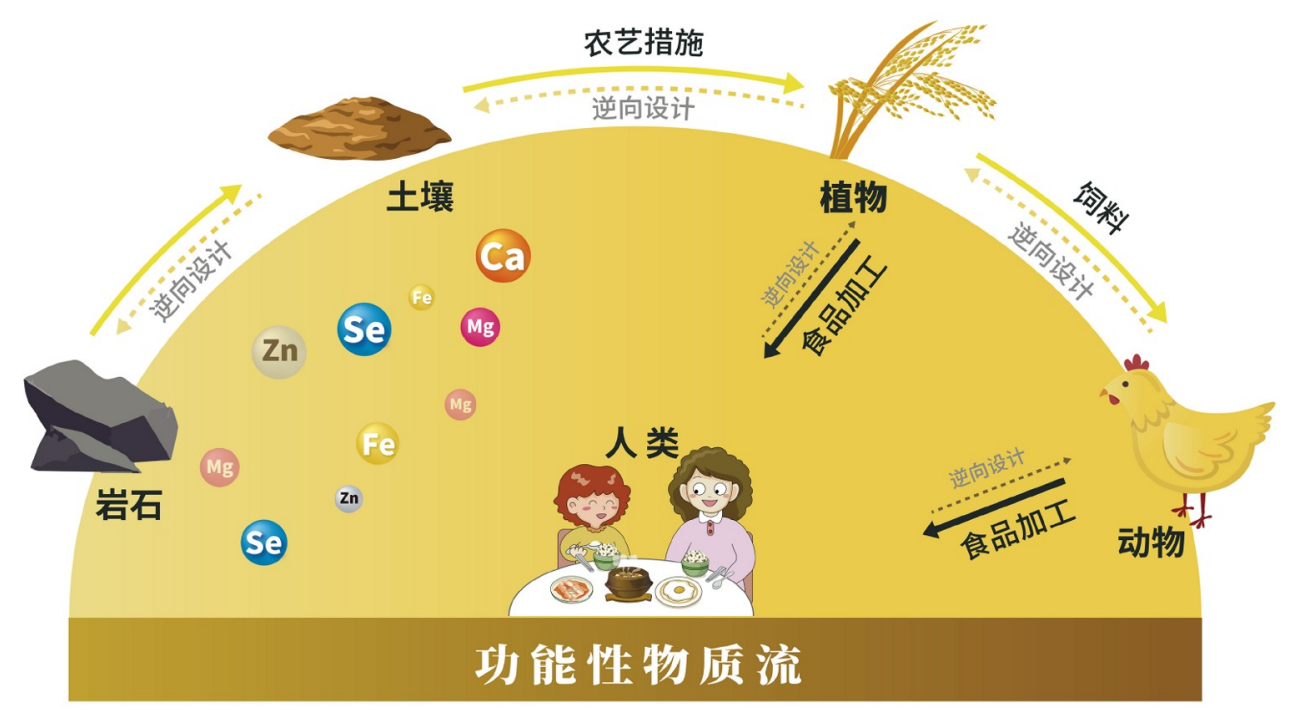

图 1 (网络版彩色)功能农业研究中功能成分物质流

Figure 1 (Color online) Material flow of functional components in functional agriculture research

(图2).

在功能成分物质流的传输规律、调控技术和评价 方法上, 取得了一系列进展.

\section{1 成土母质和过程对土壤功能物质影响的研究}

岩石风化形成成土母质，成土母质在生物作用下 形成的综合产物即为土壤，岩石与土壤中矿物质及养 分息息相关，同时外源物质的输人也会影响土壤的成 分. Wang等人 ${ }^{[8]}$ 将中国长寿地区饮用水、土壤和粮食 中的微量元素含量特征及与非长寿地区的差异进行了 探讨. 结果发现, 长寿区饮水、土壤和粮食中有益微量 元素总量占微量元素总量的比例较高，而有害元素总 量占微量元素总量的比例较低，进而得出人的寿命与 矿物质地理分布有关这一结论.

土地质量地球化学调查是了解土壤资源空间分布 规律的重要技术手段, 也是实现天然特色资源高效化

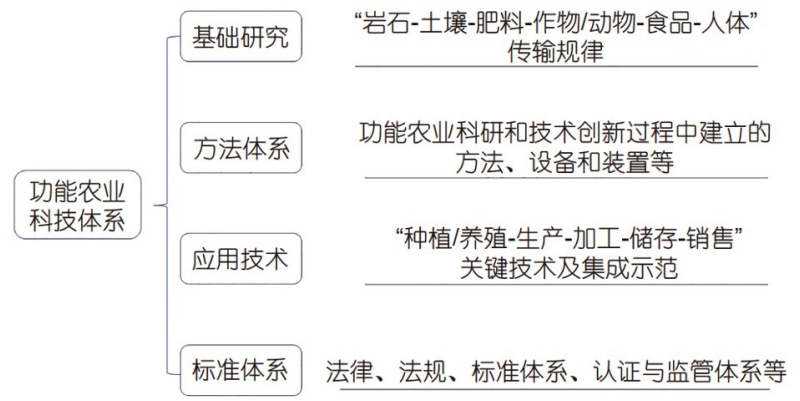

图 2 功能农业科技体系

Figure 2 Functional agriculture science and technology system
利用的前提，且有利于确定区域功能农业的优先发展. 其中，江西、广西、陕西、湖北、河北、宁夏等省区 已充分调查了 22 种成分的地球化学分布特征, 并分析 其影响因素如pH等(王晓丽，待发表). 此外，探明和开 采天然矿石, 并将其研磨成粉, 按照配比制成肥料如磷 肥、硒营养强化剂等是实现天然特色高效利用的另一 个重要途径.

\section{2 功能成分在土壤-作物间迁移转化规律}

土壤和生物有机体中营养成分、有害成分的化学 形态多样, 且不同形态之间的转化是复杂的, 土壤中的 成分被植物吸收后, 代谢转化为其他形态, 进人人体后 被吸收. 土壤中的成分可分为生物可利用和生物不可 利用两大类, 也称为土壤有效成分和非有效成分. 土壤 本身的物理化学性质如 $\mathrm{pH}$ 、土壤含水率、非目标成分 含量和形态、植物根系分泌物、微生物群落结构等均 会影响土壤成分的吸收率. 因此，探究功能成分在 土壤-作物间的迁移转化规律, 准确测定土壤中矿物质 含量及形态是功能农业科研工作和技术创新的重要 问题.

\subsection{1 人工模拟根际吸收实验系统}

功能农业的目的是生产定量含有某种或者某几种 矿物质的农产品, 开发土壤矿物质形态技术及建立吸 收预测模型是功能农业重要的研究方向. 根据矿物质 在土壤-土壤溶液-作物根际-植株-可食部分的传送过 程，通过人工模拟根际吸收实验系统(artificial root ex- 
perimental system, ARE system)(图3)探究矿物质从土壤 到土壤溶液、从土壤溶液到根系表面交换, 再到植株 转运的过程机制 ${ }^{[9,10]}$.

\subsection{2 土壤中矿物质生物的有效性及评价方法}

土壤成分含量及形态一直处于动态变化中. 以硒 为例, 硒甲基化过程形成的气态硒会进人大气, 或转变 成可溶态或以颗粒态进人水体. 而土壤成分的生物有 效性受到矿化过程中土壤 $\mathrm{pH} 、 \mathrm{Eh}$ 、有机质等的影响. 有机质可能固定土壤中的硒, 会显著降低硒的生物有 效性; 但土壤中的有机质结合硒可以缓慢释放到土壤 溶液中; 此外, 土壤有机改良剂对土壤硒生物有效性有 一定的影响 ${ }^{[11]}$. 宁夏中卫地区土壤(碱性土壤)总硒含量 较广西、恩施等高硒地区的含量低, 但土壤有效性硒 比广西、恩施等高硒地区高5倍左右(Farooq Muham$\operatorname{mad}$ Raza, 待发表).

目前, 土壤有效硒的分析测定尚无统一的标准方 法. 学者针对植物种类、土壤类型分别提出了不同的 土壤有效硒的分析方法. 盆栽和田间试验应用较多的 测定方法主要包括化学浸提法、梯度薄膜扩散技术 (diffusive gradient in thin-films technique, DGT)和新的 研究方法一一道南膜技术. DGT能更好地模拟生物体 对重金属/营养盐的吸收过程, 并提供分辨率远高于传 统方法的二维剖面图像 ${ }^{[12]}$.

\subsection{3 作物中功能成分转运的机理机制}

功能成分的吸收转运机理机制是研究矿物质在植 物生长阶段传输规律和调控技术的重要基础. 以硒为 例, 植物主要从土壤中吸收水溶性硒, 包括部分有机
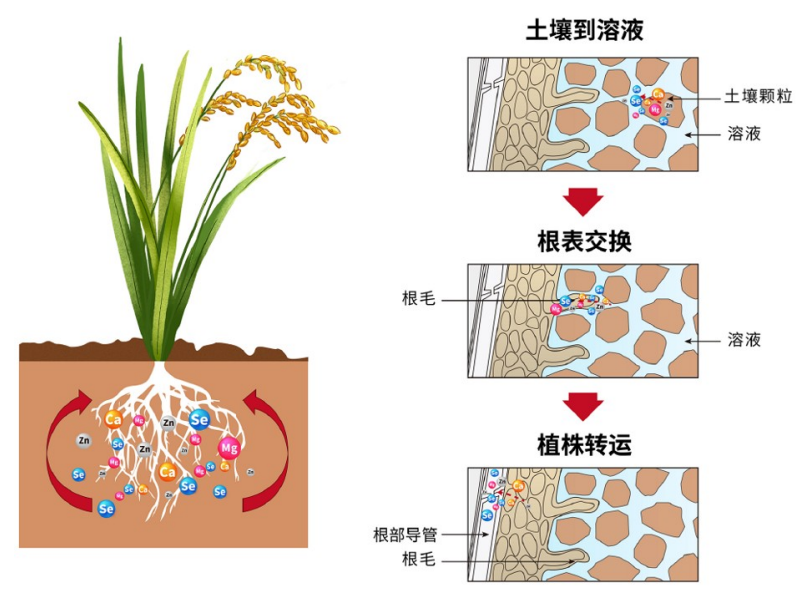

图 3 (网络版彩色)ARE系统概念图. 修改自文献[10,11]

Figure 3 (Color online) Concept diagram of ARE system. Revised from Refs. [10,11]
硒、硒酸盐和亚硒酸盐. 植物对硒酸盐的主动吸收通 过高亲和力的硫酸盐转运子完成, 磷酸盐可以调节亚 硒酸盐的吸收, 磷酸盐转运子在亚硒酸盐的主动吸收 过程中也有重要作用 ${ }^{[9]}$. 硒酸盐被吸收到植物体之后 会很快从根部转移到地上部, 在叶片中被还原成亚硒 酸盐, 进而转化为有机硒化合物进人其他组织; 而被吸 收的亚硒酸盐及其代谢产物主要积累在根部, 极少转 移到地上部, 进入植物体中的硒转化为含硒氨基酸和 硒蛋白参与植物的代谢 ${ }^{[13,14]}$. Zhang等人 ${ }^{[14]}$ 以Xiushui 48和S. Andrea两个品种的水稻作为试验材料, 切下其 根部在营养液中进行培养. 研究表明, $\mathrm{Na}_{2} \mathrm{SO}_{3}$ 与 $\mathrm{Na}_{2} \mathrm{SeO}_{3}$ 可能共用一个吸收通道, 而 $\mathrm{Na}_{2} \mathrm{SO}_{3}$ 能显著抑制 两个品种根系对 $\mathrm{Na}_{2} \mathrm{SeO}_{3}$ 的吸收. Zhang等人 ${ }^{[14]}$ 发现, $\mathrm{ZnCl}_{2}$ 可能通过抑制半胱氨酸合酶活性而显著降低两 个品种对 $\mathrm{Na}_{2} \mathrm{SeO}_{3}$ 的吸收, 并推测半胱氨酸合成酶活性 的差异是导致亚硒酸盐吸收差异的原因之一. 同位素 是研究土壤成分生物地球化学循环过程的重要手段. 朱建明等人 ${ }^{[15]}$ 通过测定玉米中硒同位素的组成发现, 玉米中硒同位素分馏更多发生在叶片中，植物中硒同 位素组成的变化范围相对较小.

\section{3 超积累植物}

超积累植物的研究可应用于植物修复污染土壤和 研发矿物质补充剂, 解决“隐性饥饿”问题. 超积累植物 是指能超量吸收重金属并将其运移到地上部积累的植 物. 以硒为例, 硒的超积累植物有壸瓶碎米荠、沙漠王 羽和双沟黄芪. 壸瓶碎米荠是在我国发现的硒超积累 植物, 根部硒的积累量高达 $8000 \mathrm{mg} / \mathrm{kg}$ (干重), 叶片中 硒的积累量也高达 $3000 \mathrm{mg} / \mathrm{kg}$ (干重). 累积形式为硒代 胱氨酸 $\left(\mathrm{SeCys}_{2}\right)^{[16]}$. 表1总结了已发现的超积累植物及 其特性.

\section{4 功能农业的环境效应}

\subsection{1 功能成分的植物保护作用}

功能农业中对功能成分的研究范围覆盖了从缺乏 到过量, 从植物保护角度的矿物成分研究与评估极为 重要. 以硒为例, $\mathrm{Wu}$ 等人 ${ }^{[31]}$ 研究发现, 亚硒酸盐显著抑 制真菌病原菌的孢子萌发和菌丝生长, 对灰霉菌的生 长具有抑制作用; 但硒含量过高会对植物产生毒害作 用, 过量喷施硒可使豇豆叶片发生斑状毒害病变症 状 ${ }^{[32]}$. 研究发现, As、Al、Mg、Mo等13种元素均参与 植物代谢, 具有一定的植物保护作用 ${ }^{[33,34]}$. 
表 1 超积累植物

Table 1 Hyperaccumulator

\begin{tabular}{|c|c|c|}
\hline 植物类型 & 富集重金属类型 & 分布 \\
\hline 印度芥菜 ${ }^{[17]}$ & $\begin{array}{c}\text { Caesium }(\mathrm{Cs}) 、 \text { lead } \\
(\mathrm{Pb}) 、 \text { selenium }(\mathrm{Se}), \\
\text { cadmium }(\mathrm{Cd})\end{array}$ & $\begin{array}{c}\text { 美国伊利诺伊州、 } \\
\text { 新泽西州、 } \\
\text { 加利福尼亚州 }\end{array}$ \\
\hline 向日葵 ${ }^{[18]}$ & $\begin{array}{l}\text { Strontium }(\mathrm{Sr}) 、 \text { lead } \\
(\mathrm{Pb}) 、 \text { caesium }(\mathrm{Cs}) 、 \\
\text { manganese }(\mathrm{Mn})\end{array}$ & 全球 \\
\hline 西洋樱草 ${ }^{[18]}$ & \multirow{3}{*}{ Nickel (Ni) } & 中国、日本 \\
\hline 九节木属 ${ }^{[18]}$ & & 中国 \\
\hline 奕树 ${ }^{[18]}$ & & 中国 \\
\hline 蜈蚣草 ${ }^{[19]}$ & \multirow{3}{*}{ Arsenic (As) } & 中国 \\
\hline 大叶井口边草 ${ }^{[19]}$ & & 中国东部 \\
\hline 凤尾硕 ${ }^{[19]}$ & & 欧洲、非洲 \\
\hline 宝山堇菜 ${ }^{[20,21]}$ & \multirow{5}{*}{ Cadmium $(\mathrm{Cd})$} & 中国 \\
\hline 龙葵 ${ }^{[20,21]}$ & & 欧洲的温带和热带 \\
\hline 小飞扬草 ${ }^{[20,21]}$ & & 非洲、美洲 \\
\hline 羊齿类铁角䯾 $[20,21]$ & & 中国 \\
\hline 野生苋 ${ }^{[20,21]}$ & & 北美洲、亚洲 \\
\hline 水蓼 ${ }^{[22,23]}$ & \multirow{3}{*}{ Manganese (Mn) } & 亚洲、欧洲、北美洲 \\
\hline $\begin{array}{l}\text { 商陆 }^{[23,24]} \\
\text { 杜板归 }\end{array}$ & & $\begin{array}{c}\text { 亚洲东部 } \\
\text { 中国 }\end{array}$ \\
\hline 蓄麻 ${ }^{[24,25]}$ & & 全球的热带区域 \\
\hline 海州香薷 ${ }^{[24,25]}$ & \multirow{3}{*}{ Copper $(\mathrm{Cu})$} & 亚洲、北美洲 \\
\hline 鸭跖草 ${ }^{[24,25]}$ & & 亚洲、北美洲 \\
\hline 高山甘薯 ${ }^{[24,25]}$ & & 北半球 $40^{\circ} \mathrm{N}$ \\
\hline $\begin{array}{c}\text { 紫花苜蕧 } \\
{ }^{[26]} \\
\text { 大豆 }^{[26]}\end{array}$ & Uranium (U) & $\begin{array}{l}\text { 全球 } \\
\text { 全球 }\end{array}$ \\
\hline 遏蓝菜 ${ }^{[27]}$ & \multirow{4}{*}{ Selenium (Se) } & 中国、美国 \\
\hline 壶瓶碎米荠 ${ }^{[27]}$ & & 湖南、湖北 \\
\hline 美国沙漠王羽 ${ }^{[27]}$ & & 美国加利福尼亚州 \\
\hline 双沟黄芪 ${ }^{[27]}$ & & 美国加利福尼亚州 \\
\hline 油菜 ${ }^{[28,29]}$ & \multirow{2}{*}{ Zinc (Zn) } & 全球 \\
\hline 东南景天 ${ }^{[28,29]}$ & & 东亚 \\
\hline 李氏禾 ${ }^{[30]}$ & Chromium (Cr) & 全球热带区域 \\
\hline
\end{tabular}

\subsection{2 功能成分与土壤生物的相互作用关系}

植物的根际聚居着大量生物, 包括细菌、放线 菌、真菌、藻、原生动物和病毒等, 并与根系分泌物 相互影响, 形成特殊的微生态环境, 并对功能成分的迁 移、转化具有重要作用.

一方面, 土壤生物能影响功能成分的迁移转化, 如
根际微生物 $\alpha$-变形菌纲和硝化螺旋菌纲对壸瓶碎米荠 中硒的吸收、积累有重要作用 ${ }^{[35]}$. 利用土壤生物对功 能成分的作用，可以进行作物营养强化. 研究表明，接 种富硒细菌(窄食单胞菌、芽狍杆菌、肠杆菌和假单 胞菌)显著增加了小麦植株组织中的硒浓度 ${ }^{[36]}$, 将富硒 菌与丛枝菌根真菌(球囊球藻)共同接种到小麦植株, 通 过协同作用能显著提高籽粒硒含量 ${ }^{[37]}$. 许多根际微生 物被广泛应用于作物 $\mathrm{Fe}^{[38]}$ 及 $\mathrm{Zn}^{[39]}$ 等功能成分强化中, 取得了良好的营养强化效果. 另一方面, 土壤中功能成 分的改变能引起土壤动物多样性的改变, 引起土壤动 物个体行为功能的改变. 随着人们对土壤生物的多样 性及其生态重要性的广泛关注，土壤生物如线虫、原 生动物、蚯蚓及螨类越来越多地被用于土壤环境质量 监控 ${ }^{[40]}$. 研究发现, 与对照组相比, 添加外源硒后, 土壤 线虫群落多样性显著降低 ${ }^{[41]}$. 对农业土壤施加含锌污 泥后，在土壤中也观察到类似的线虫群落多样性降低

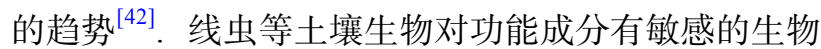
指示作用，因此，可以利用土壤生物的环境指示作用， 对功能农业土壤进行评价、管理及修复，以保证农业 资源的可持续绿色发展(宋佳平, 待发表).

\subsection{3 作物中不同矿物质间的相互作用关系}

作物吸收土壤矿物质过程中，不同物质存在拮抗 和协同等相互作用. 在植物吸收矿物质时, 多数阳离子 之间存在一定的竞争关系，如钲可能影响镁、锌的吸 收 ${ }^{[43,44]}$; 阴离子硒也能促进碘离子的吸收 ${ }^{[45]}$. Zhang等 人 $^{[46]}$ 监测了高硒、高镉地区的土壤、玉米根、茎、叶 及玉米粒中 Se和 Cd含量. 结果发现, 土壤硒与镉的可利 用摩尔比 $\leqslant 0.7$ 时会提高植物镉的富集，利用 SAXHPLC-ICP-MS可检测出叶片中的硒镉络合物，硒对镉 的吸收有一定的抑制作用.

甲基录是毒性最强的录化合物. Korbas等人 ${ }^{[47]}$ 利 用同步加速器X射线吸收光谱研究脑组织中硒与录的 化学形态. 结果发现, 硒与采以一定的摩尔比例 (1:1 1:1.3)进行结合, 可以降低甲基录的毒性; 且大多 数丞和硒都集中在灰质中, 硒几乎可以忽略不计. 此结 果表明，中枢神经系统的关键排毒途径为元素间相互 作用关系的研究提供了新手段.

\subsection{4 针对功能肥料的控害技术}

施加功能肥料可以增加作物的硒含量，提高作物 产量, 改善作物品质, 增加其对干旱、盐害、冻害、重 金属毒害等逆境胁迫的抵抗能力，但是过量的功能成 分也会对人与动物产生毒害. 高浓度硒酸钠处理对苗 
期堇叶碎米荠具有明显的毒害作用 ${ }^{[48]}$. 缓控释肥料可 以减缓肥料中功能成分的释放速度，按照设定速度在 作物特定生育期释放功能成分, 避免功能肥料对作物 产生毒害作用 ${ }^{[49]}$.

\section{5 功能农业长期科学试验站}

功能农业生产实践中需要了解在土壤、气候、物 种等因素综合作用下，功能肥料在土壤中的长期积累 效应, 在代表性区域建立功能农业长期科学试验站. 洛 桑试验站的长期定位试验影响了世界各地的农业科研 工作者, 建立至今已经累计保存了约 30 万份土壤、植 物、肥料样品, 为研究元素循环、环境变化提供了极 为宝贵的材料. 洛桑试验站长期定位试验的土壤碳库 变化动态表明, 长期施用化肥 $(\mathrm{N} 、 \mathrm{P} 、 \mathrm{~K})$ 使土壤有机碳 增加, 这是施肥促进作物生长, 增加进人土壤作物残茬 的缘故 ${ }^{[50]}$. 其后, 我国在南京浦口、苏州园区、山西东 阳等地, 陆续建立了多个国家长期科学试验站, 研究不 同地区的地球化学特征以及功能农业实践.

\section{6 食品加工过程矿物质形态变化规律}

不同功能农产品加工过程中水分、氧化还原电位 点的变化、温度和粒度等均会发生变化, 而功能成分 的变化情况是最需要被关注的研究内容. 蒸、煮、炸 和榕4种常用的烹调方法, 对不同食物中硒含量和形态 具有一定的影响. 在蒸、煮、炸和榕等过程中, SeMet 的损失率分别为 $13.5 \% 、 24.0 \% 、 3.1 \%$ 和 $46.9 \%$; 水煮 谷物中硒半胱氨酸 $\left(\mathrm{SeCys}_{2}\right)$ 和甲基硒半胱氨酸 $(\mathrm{Se}-$ $\mathrm{MeCys}$ )完全丢失; 黄豆中由于残留硒的含量较高, 总硒 的损失为 $49.1 \%{ }^{[51]}$. 煮制的黄豆矿物质元素损失较多, 且随煮制时间的增加，矿质元素含量总体呈现降低的 趋势. 因此, 建议富含硒的谷类食品采用蒸、炸方式较 好 $^{[52]}$.

此外, 罐藏、发酵等生产工艺中矿物质含量及形 态变化也是功能农产品的研究重点. 郝飞龙等人 ${ }^{[53]}$ 以 山西燕麦为原料制备 $\beta$-葡聚糖, 并对其流变学特性进 行研究. 结果发现, 燕麦 $\beta$-葡聚糖溶液黏度与其浓度及 $\mathrm{pH}$ 成正比, 与溶液温度成反比; 流体弹性行为增加而黏 性行为减弱; 随着流体温度的升高, 燕麦 $\beta$-葡聚糖黏性 和弹性行为均减弱. 王晓闻等人 ${ }^{[54]}$ 制作了红柊燕麦核 桃营养早餐和富硒燕麦复合益生菌发酵乳，分析其咜 藏过程中品质特性. 结果表明, 富硒燕麦酸奶的稳定性 能较好; 牛奶奶酪和黑豆豆奶牛奶奶酪分别在 30 和 $60 \mathrm{~d}$
的咜藏过程中物质组成成分存在差异.

\section{7 功能农产品与人体健康研究}

《中国居民膳食营养素参考摄人量》2013修订 版 ${ }^{[55]}$ 简介中报告了中国居民不同性别、年龄、体重、 身高和体力活动的膳食蛋白质、脂肪、矿物质及其他 营养成分的推荐摄人量或适宜摄人量 ${ }^{[5]}$. 功能农业的 目标营养素摄人量参考此标准，第一阶段目标重点关 注实现“人群缺啥补啥, 缺多少补多少”, 利用功能农产 品补充人体矿物质及微量元素营养. 第二阶段是功能 农产品中功能成分的生物有效性需要的研究, 评价方 法体系包括细胞、动物实验、人工模拟胃肠、人群 干预.

\subsection{1 人体矿物质摄入量研究}

人体必需的 24 种矿物质元素无法自身合成，需从 外界获取. 摄人过多或者不足都会对人体健康产生危 害, 摄人量的多少受年龄、性别、身体状况、环境、 工作状况等因素的影响.

以硒元素为例, 学者开展了石台县自然环境硒含 量与人群硒摄人量的潜在关系研究. Long等人 ${ }^{[56]}$ 检测 了安徽石台县食物硒的含量、居民发硒和血浆硒含量, 并以此计算得到石台居民的日硒摄人量为 $298.4 \mu \mathrm{g} /(\mathrm{d}$ 人), 是我国推荐营养素摄人量 $(60 \mu \mathrm{g} /(\mathrm{d}$ 人))的 5 倍左右. 恩施 3 个村庄居民的发硒含量为北风崖 $2.40 \pm$ $1.43 \mathrm{mg} / \mathrm{kg}$ 、老熊坡 $3.07 \pm 1.52 \mathrm{mg} / \mathrm{kg}$ 、桑树坡 $2.48 \pm$ $2.00 \mathrm{mg} / \mathrm{kg}$. 北风崖居民的硒日摄人量为 $527 \pm 212 \mu \mathrm{g}$, 高于桑树坡居民的 $370 \pm 175 \mu \mathrm{g}$, 北丰崖居民的发硒含 量低于桑树坡居民的 $(P<0.05)$. 同时, 发硒与水稻硒(当 地居民摄入硒的主要来源)之间无显著相关，头发中硒 的含量长期依赖于环境条件和硒摄人量 ${ }^{[57]}$. 矿物质的 摄人量并不是越多越好, 必须结合地理环境、人群特 征等多种因素进行综合考虑, 所以探究矿物质摄人量 的适宜范围也是功能农业需要重点研究的问题.

\subsection{2 功能成分人体吸收预测模型}

功能成分的摄人量并不等于人体对其的吸收量, 因此人体对功能成分的吸收利用效率与预测是功能农 业一项重要的研究内容. 建立功能成分人体吸收预测 模型有助于预测不同摄人量对人体健康的影响, 帮助 确定功能成分摄人量的标准. Gao等人 ${ }^{[58]}$ 调查了苏州 地区常见的22种食物和发硒含量. 结果发现, 较高的发 硒含量对应较高的每日硒摄人量, 反之亦然. 并以此建 立了苏州地区人群日硒摄人与发硒中硒含量的模型, 
硒日摄人量与发硒的关系为: 女性每日硒摄人量 $=$ $0.0887 \mathrm{Se}_{\text {hair }}+16.1\left(R^{2}=0.9798, n=7\right)$; 男性每日硒摄人量 $=$ $0.0803 \mathrm{Se}_{\text {hair }}+14.2\left(R^{2}=0.9367, n=7\right)$.

\subsection{3人工胃肠模拟系统}

人工胃肠模拟系统是研究功能成分与人体健康效 应的重要方法. 人工胃肠模拟评估系统有助于研究功 能食品在人体内的吸收转化情况, 帮助了解矿物质成 分的摄人及吸收过程. Sun等人 ${ }^{[59]}$ 搭建了 SHIME(Simulator of the Human Intestinal Tract)系统模拟人工胃肠消 化过程, 并依此提出, 硒生物可给性为从胃肠道食物基 质中释放的食物中硒的分数(用于肠道吸收); 硒生物有 效性为食物中硒通过肠细胞转移到血液和身体中的比 例(用于全身代谢).

陆晓奇 ${ }^{[60]}$ 采用胃肠模拟系统研究了 5 种典型的富 硒植物材料中硒的溶出率. 结果发现, 富硒小麦和富硒 大豆的硒溶出率显著高于其他植物, 壶瓶碎米荠的硒 溶出率最低.

\subsection{4 利用功能产品进行健康千预研究}

功能成分的摄入量与人体健康紧密相关, 确定适 宜的摄人量范围, 保障居民健康改善的同时, 并能最大 限度控制风险, 因此, 功能成分摄人量的上下限值是功 能农业研究的重点内容之一. Lyons等人 ${ }^{[61]}$ 选择了 40 70岁的健康老年男性作为试验对象, 分别对他们干 预未强化的小麦、生物强化小麦和合成硒蛋氨酸强化 小麦制成的全麦饼干. 结果显示, 食用生物营养强化饼 干组试验者在半年内的血浆硒浓度呈显著增高的趋势. Waters等人 ${ }^{[62]}$ 研究了犬类健康与硒含量的关系, 发现 犬类健康与硒含量呈Mertz的剂量反应模型U型曲线, 说明“越多不一定越好”。营养预防癌症试验中补充硒 可降低人类前列腺癌风险的影响; 趾硒含量低的男性 可以通过补充硒减少前列腺DNA损伤, 而高趾硒含量 的男性无法从补充硒中获益 ${ }^{[63]}$.

\subsection{5 硒与新型冠状病毒的研究}

前人研究表明，某些RNA病毒如艾滋病毒(human immunodeficiency virus, HIV)、埃博拉病毒、柯萨奇 病毒、SARS病毒等均与人体硒水平有显著相关性, 甚 至在非洲地区, 硒缺乏一直被用作HIV-1 阳性率的替代 指标 ${ }^{[64]}$. 2020年初, 全球爆发新型冠状病毒(SARS$\mathrm{CoV}-2$, 简称新冠病毒)疫情. 硒因其具有抗氧化、维护 机体免疫功能和抗病毒突变等特性, 可能对新型冠状 病毒肺炎(COVID-19, 简称新冠肺炎)的治疗具有重要 的作用. 为验证这一猜测, 很多学者开展了相关研究.
从湖北的土壤硒含量和新冠肺炎患者治愈率数据来看, 土壤硒含量极高区的恩施市治愈率为 $36.4 \%$, 远高于湖 北其他城市的总治愈率 $13.1 \%{ }^{[65]}$. 国外一些关于硒与新 冠病毒的研究表明, 德国存活的COVID-19患者血清硒 水平高于死亡患者 ${ }^{[66]}$, 韩国的COVID-19患者和非肺炎 患者均明显缺乏硒 ${ }^{[67]}$. 这些结果证明硒在对新冠肺炎 的治疗中具有较大意义.

\section{8 天然生物营养强化项目}

天然生物营养强化项目(Natural Biofortification Program, NBP)由国际硒研究学会发起, 旨在探索“天 然富硒区环境土壤、水和食物中的硒与人体健康之间 的实证关系”, 以土壤硒/硒结合形态数据库、典型农作 物及动物产品硒/硒形态数据库、典型动植物产品硒的 生物有效性、人体硒相关参数及健康指标、食品安全 硒摄人量的再评价为重点研究内容. 目前, NBP项目已 在安徽石台、湖北恩施、江西宜春建立了首批研究基 地. 对江西明月山两个村庄的土壤总硒含量、作物硒 含量、村庄居民发硒及血浆硒含量与人体健康相关参 数的研究发现, 土壤、作物与饮食硒摄人量具有相关 性, 血浆GPx酶活性和血浆硒蛋白P含量可用于评估低 硒地区人体硒水平(林锦钰, 待发表). 安徽石台县 4 个 村庄土壤总硒含量及村庄居民发硒含量的研究发现, 土壤、作物与饮食硒摄入量具有显著相关性 ${ }^{[56]}$.

\section{9 基准物质}

由于功能农业研究涉及品种多、范围广、链条长, 因此, 需要多领域、多国科学家及研究组合作. 为使广 泛合作研究的结果可以对比, 需要对其使用的试验材 料进行严格的标准化. 故此, Yin等人 ${ }^{[68]}$ 研发了基准物 质, 以基准功能肥料和基准功能食材为主, 也包括养殖 用的基准材料和食用菌种植的基准基质，这些基准物 质均成分明确、含量清晰.

\section{9 .1 基准功能肥料}

施用肥料是改善土壤、提高产品功能成分含量的 主要手段. 不同于普通肥料, 基准功能肥料是用于作物 对功能成分吸收及转化模型、物质间相互作用关系等 多类研究的基准物质, 有利于国际、国内不同研究机 构试验及研究数据比对. Yin等人 ${ }^{[68]}$ 研制了多款基准硒 肥、基准锌肥、基准水溶性硒肥、基准水溶性锌肥等 基准功能肥, 这些基准功能肥具有明确的矿物质含 量和形态组成(表2). 粉末性基准硒肥中总硒含量为 
表 2 水溶性基准硒肥和硒形态含量 ${ }^{a)}$

Table 2 Water-soluble benchmark selenium fertilizer and selenium form content

\begin{tabular}{rccccccc}
\hline 基准肥料 & 总硒 $(\mathrm{mg} / \mathrm{L})$ & $\mathrm{SeCys}_{2}(\%)$ & $\mathrm{MeSeCys}(\%)$ & $\mathrm{Se}^{4+}(\%)$ & $\left.\operatorname{SeMet}^{2} \%\right)$ & $\mathrm{Se}^{6+}(\%)$ & 其他 $(\%)$ \\
\hline 水溶肥(A) & 5000 & 17.1 & 10.7 & - & 2.3 & - & 69.9 \\
水溶肥(B) & 5000 & - & - & 9.1 & - & - & 90.9 \\
\hline
\end{tabular}

a) “-”表示未检出

$11088 \mathrm{mg} / \mathrm{kg}$, 其中水溶态硒、可交换态硒和生物有效 态硒分别占比为 $9.5 \% 、 0.6 \%$ 和 $10.1 \%$.

\subsection{2 基准功能食材}

基准功能食材具有明确的矿物质含量和形态，可 用于食品加工工艺的研究、富功能成分产品的研制, 以及特殊膳食用食品的开发. 基准功能食材的推出可 以方便不同研究机构开展某种功能食材的共性特征评 价和加工工艺研究, 利于形成共享数据库. Yin等人 ${ }^{[68]}$ 研制了硒、锌、钙等基准功能食材, 其中包括富硒西 兰花、富硒玉米粉, 其成分如表3所示.

\subsection{0 功能农业研究的新技术、新方法、新装备}

功能成分传统检测技术一般需要3 14 d, 基于满足 研究和产业化中对功能成分检测时效性的要求, 需开 发快速检测技术. Schomburg等人 ${ }^{[69]}$ 开发了硒蛋白检测 试剂盒, 可用于人、大小鼠、豚鼠、兔、犬、牛、 羊、猴、猪、昆虫、植物、农残、鱼类等样品中硒蛋 白P的快速检测. 刘广等人 ${ }^{[70]}$ 开发的硒快速检测系统由 预处理装置和硒检测仪组成, 适用于对农产品、头 发、尿液等人体组织中硒含量的快速检测, $30 \mathrm{~min}$ 可 得到检测结果. 采用物育种技术已培育出硒高效油菜

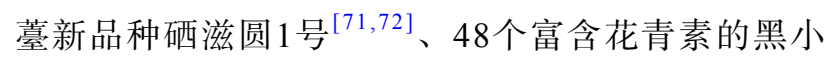
麦 ${ }^{[73,74]}$ 、高锌中铁小麦品种 ${ }^{[75]}$ 、高 $\beta$-胡萝卜素甘 薯 $^{[76]}$ 、富含抗性淀粉的水稻R7954 $4^{[77,78]}$ 等一系列的优 质品种.

我国市场上的功能产品名目繁多, 为了使功能成 分含量标准化, 需要逐步制定功能农业标准体系和认 证体系. 其中, 富硒农副产品的标准发展最快, 如《富
硒农产品》《富硒马筩著》和《富硒谷物》等一系列 的行业标准已获颁布或立项，并在江苏、山西、河北 等建立了FAST Tracing全过程智慧溯源系统. 此外, 围 绕功能农产品的精准配肥、收储、加工等技术, 我国 科研团队还研发了功能农业专用农田土壤矿素的空间 精准评价、智慧配肥、智慧功能育苗工厂、智慧精准 栽培、功能稻米精准收储等系统性智慧生产技术及 设备.

\section{3 我国“十四五”功能农业发展目标与建议}

功能农业作为农产品提质增效的新思路, 是农业 供给侧结构性改革的重要路径，可助力我国“质量兴 农”与“乡村振兴”战略, 能够解决居民矿物质缺乏带来 的“隐性饥饿”问题，对于服务“健康中国”战略也具有 十分重大的意义，因此被香山科学会议第669次学术讨 论会认为是世界农业发展的新趋势. 历经13年的发展, 我国功能农业学科体系初见雉形, 科技创新体系也在 初步建立. 2019年6月17日，国务院下发国发(2019)12 号文件《关于促进乡村产业振兴的指导意见》，提出 发展功能农业. 农业农村部在乡村产业规划及国家粮 食和物资储备局在优质粮食工程中也提出支持该方向. 面对国家战略需求和地方政府对发展功能农业的迫切 需要, 功能农业从学科体系到科技创新体系仍有很 多问题尚待解决, 整体上创新链断链现象普遍, 缺乏国 家平台, 研究的方法体系有待建立, 缺少支持功能农业 系统创新的重大项目，产学研结合协同攻关的体制机 制尚未形成, 标准研究和制定不能满足产业发展需 求等.

表 3 富硒西兰花、玉米基准食材硒含量与形态组成 ${ }^{a)}$

Table 3 Selenium content and morphological composition of selenium-enriched broccoli and corn

\begin{tabular}{cccccccc}
\hline 食材 & 总硒 $(\mathrm{mg} / \mathrm{L})$ & $\mathrm{SeCys}_{2}(\%)$ & $\mathrm{MeSeCys}(\%)$ & $\mathrm{Se}^{4+}(\%)$ & $\mathrm{SeMet}(\%)$ & $\mathrm{Se}^{6+}(\%)$ & 其他 $(\%)$ \\
\hline 西兰花 & 300 & 10.1 & 22.5 & - & 57.5 & - & 9.9 \\
玉米 & 50 & 21.7 & - & - & 74.9 & - & 3.4 \\
\hline
\end{tabular}

a) “-”表示未检出 


\section{1 功能农业发展重要性和着力点}

关于功能农业的发展重要性, 赵其国院士总结了 8 点. (1) 紧迫性: 农业需要新技术支撑质量再提升, “隐性 饥饿”问题日益受到关注; (2) 重要性: 服务于“质量兴 农”和“健康中国”战略; (3) 必要性: 功能农业可满足我 国消费者对农产品优质化、营养化、功能化需求; (4) 现实性: 与当前农业生产和人们的生活紧密相连, 紧扣 “三农”问题; (5) 社会性: 可促进农业提质增效, 具有“农 民增收、农业增效、人民增寿”的三增效应，有利于提 高国民生活质量与健康水平, 具有重大的社会意义; (6) 发展性: 农业从追求“量”到追求“质”的新需求; (7) 前景 性：支撑食品的营养保健性和科技发展是中国至2050 年农业科技发展新需求; (8) 国际性: 功能农业作为世 界农业的发展趋势, 我国率先布局将大大提升农业国 际竞争力.

关于未来推进的着力点, 赵其国院士指出功能农 业的发展需要向 5 个方向推进. (1) 深化: 功能农业概念 及研究的深化; (2) 实化: 从概念、理论到产业实践的 落实; (3) 样板化: 高标准打造一批功能农业样板; (4) 规模化: 实现功能农业的规模化示范与推广; (5) 系统 化: 研究方法及产业创新、社会化服务体系建设的系 统化.

\section{2 我国功能农业“十四五”期间的发展目标}

我国功能农业发展的目标是逐步建立功能农业学 科体系, 包括功能农业研究方法体系、应用与示范体 系在内的产业创新体系, 形成功能农业标准体系、认 证与监管体系、法律法规体系、产业及联盟体系等在 内的社会化服务与产业支撑体系. 重点合作发展FAST Tracing全过程智慧溯源系统, 建立功能农业标准体系, 如功能农业产地环境标准、种植生产技术规程、检测 标准、产品标准等, 建立功能农业产品、功能粮油等 认证与监管体系，在我国及“一带一路”沿线国家合作 推广中国引领的技术标准.

\section{3 我国功能农业“十四五”期间的发展建议}

为发挥功能农业的科技支撑作用，更好服务我国
“乡村振兴”和“健康中国” 战略，通过农产品功能化提 质, 促进农业产业增效, 进一步丰富我国农业现代化内 涵, 建议相关部委发挥职能优势, 针对性支持功能农业 原创成果拓展、深化和产业应用, 可从八方面人手加 以推进. (1) 加强顶层设计: 支持由国家功能农业科技 创新联盟组织, 作好顶层设计, 分阶段作好发展的网络 框架图, 提出具体的路线图、行动方案以及实施措施; (2) 安排重大专项: 国家相关部委将国家生态高值功能 农业综合研发任务, 列人“十四五”、“十五五”国家重点 研发计划及中长期发展规划, 鼓励省、市、县(区)制定 功能农业的发展专项规划; (3) 搭建国家平台, 组建“国 家队”: 全国研究机构合作建设农业农村部功能农业(学 科群)重点实验室、国家功能农业技术创新中心、国 家功能粮油技术创新中心等国家级研究平台; (4) 成立 咨询机构：建议依托中国科学院学部建立“国家生态高 值功能农业研究咨询委员会”, 指导建设功能农业研究 网络, 并提出结构性设置、布局与管理方案; (5) 建立 示范体系: 建立功能农业应用与示范体系, 针对重要作 物及重要区域, 融合农业食品、生物技术、人工智能, 高标准建设若干功能农业研究基地、应用示范区及科 技产业园; (6) 加快人才培养: 制定功能农业学科建设 与人才培养计划, 培养功能农业专业人才; (7) 建立健 全标准法规: 考虑到功能农业属于我国牵头推动的原 始创新领域, 我国必须在建立功能农业标准体系、认 证与监管体系、法律法规体系等方面率先布局, 为原 创成果落地提供绿色通道, 保障功能农业有序发展, 并 借机抢占制高点; (8) 建立学会联盟: 应发挥国家功能 农业科技创新联盟作用, 支持组织成立功能农业相关 学会、协会, 搭建科研与地方政府、龙头企业交流合 作平台, 建立高效协同的国内、国际功能农业科技创 新网络—FAST Network.

此外, 支持设立示范省、市针对功能农业的重点 发展领域开展应用示范，并支持和合作推进国家平台 的建设. 4 个重点领域: (1) 功能农业目的的土壤资源调 查; (2) 关键科技问题研究与集成示范; (3) 产品健康效 应评估研究与示范; (4) 研究的关键方法体系与设施 研制. 


\section{参考文献}

1 Jones G D, Droz B, Greve P, et al. Selenium deficiency risk predicted to increase under future climate change. Proc Natl Acad Sci USA, 2017, 114: $2848-2853$

2 Yu D M, Zhao L Y, Ju L H, et al. Status of energy and primary nutrients intake among Chinese population in 2015-2017 (in Chinese). Food Nutr Chin, 2021, 27: 5-10 [于冬梅, 赵丽云, 琚腊红, 等. 2015-2017年中国居民能量和主要营养素的摄人状况. 中国食物与营养, 2021, 27: 5-10]

3 Davis D R, Epp M D, Riordan H D. Changes in USDA food composition data for 43 garden crops, 1950 to 1999. J Am Coll Nutr, 2004, 23: 669682

4 Agricultural Strategy Research Group, Chinese Academy of Sciences. Agricultural Science \& Technology in China: A Roadmap to 2050 (in Chinese). Beijing: Science Press, 2009 [中国科学院农业领域战略研究组. 中国至2050年农业科技发展路线图. 北京: 科学出版社, 2009]

5 Chinese Academy of Sciences. New Trend of Science and Technology Development and Strategic Choice for 2020 (in Chinese). Beijing: Science Press, 2013 [中国科学院. 科技发展新态势与面向2020年的战略选择. 北京: 科学出版社, 2013]

6 Zhao Q G, Duan Z Q. Ecological High Value Agriculture: Theory and Practice (in Chinese). Beijing: Science Press, 2013 [赵其国, 段增强. 生态高 值农业: 理论与实践. 北京: 科学出版社, 2013]

7 Zhao Q G, Yin X B. Functional Agriculture (in Chinese). Beijing: Science Press, 2016 [赵其国, 尹雪斌. 功能农业. 北京: 科学出版社, 2016]

8 Wang S, Luo K, Ni R, et al. Assessment of elemental background values and their relation with lifespan indicators: A comparative study of Jining in Shandong Province and Guanzhong area in Shaanxi Province, northern China. Sci Total Environ, 2017, 595: 315-324

9 Zhang F C, Kang S Z, Li Z J. Numerical simulation of nutrient transfer and absorption in soil-root system I . A steady-state model of nutrient uptake by plant roots (in Chinese). J Northwest A\&F Univ (Nat Sci Ed), 2002, 30: 7-10, 15 [张富仓, 康绍忠, 李志军. 土壤-根系统养分迁移和 吸收的数值模拟 I . 植物根系吸收养分的稳态模型. 西北农林科技大学学报(自然科学版), 2002, 30: 7-10, 15]

10 Zhang F C. Mechanisms and modeling of nutrient movement at the soil-root system (in Chinese). Doctor Dissertation. Yangling: Northwest A\&F University, 2001 [张富仓. 土壤-根系统养分迁移机制及其数值模拟. 博士学位论文. 杨凌: 西北农林科技大学, 2001]

11 Wang M, Cui Z, Xue M, et al. Assessing the uptake of selenium from naturally enriched soils by maize (Zea mays L.) using diffusive gradients in thin-films technique (DGT) and traditional extractions. Sci Total Environ, 2019, 689: 1-9

12 Fang X, Luo J, Gao Y, et al. Theory and application of diffusive gradients in thin-films in the environment: High-resolution analysis and its applications in soils and sediments (in Chinese). Agro-Environ Sci, 2017, 36: 1693-1702 [房煦, 罗军, 高悦, 等. 梯度扩散薄膜技术(DGT)的理论 及其在环境中的应用 II : 土壤与沉积物原位高分辨分析中的方法与应用. 农业环境科学学报, 2017, 36: 1693-1702]

13 Wang X F, Chen S Y, Luo Z, et al. Mechanisms of selenium uptake, translocation and chemical speciation transformation in plants (in Chinese). Agric Resour Environ, 2014, 31: 539-544 [王晓芳, 陈思杨, 罗章, 等. 植物对硒的吸收转运和形态转化机制. 农业资源与环境学报, 2014, 31: 539-544]

14 Zhang L, Shi W, Wang X. Difference in selenite absorption between high- and low-selenium rice cultivars and its mechanism. Plant Soil, 2006, 282: $183-193$

15 Zhu J M, Johnson T M, Wang X L, et al. Isotope fractionation of selenium in plants (in Chinese). In: National Symposium on New Techniques and Methods in Isotope Geology, 2012. 52 [朱建明, Johnson T M, 王相力, 等. 植物中硒的同位素分馏. 见: 全国同位素地质新技术新方法与应用 学术讨论会, 2012. 52]

16 Yuan L, Zhu Y, Lin Z Q, et al. A novel selenocystine-accumulating plant in selenium-mine drainage area in Enshi, China. PLoS One, 2013, 8: e65615

17 Axelsson T, Bowman C M, Sharpe A G, et al. Amphidiploid Brassica juncea contains conserved progenitor genomes. Genome, 2000, 43: 679-688

18 Wu D, Deng Q, Geng D, et al. Content and enrichment characteristics of dominant plants on Cd, Ni, Cu in dominant plants in abandoned lead-zinc mining area (in Chinese). Guizhou Agric Sci, 2014, 42: 191-195 [吴迪, 邓琴, 耿丹, 等. 废弃铅锌矿区优势植物中镉、镍、铜含量及富集特征. 贵州农业科学, 2014, 42: 191-195]

19 Chen T B, Wei C Y, Huang Z C, et al. Characteristics of enrichment of arsenic (As) hyperaccumulator: Pteris vittata L. (in Chinese). Chin Sci Bull, 2002, 3: 207-210 [陈同斌, 韦朝阳, 黄泽春, 等. 砷超富集植物蜈蚣草及其对砷的富集特征. 科学通报, 2002, 3: 207-210]

20 Liu W, Shu W S, Lan C Y. A new cadmium (Cd) hyperaccumulator: Viola baoshanensis (in Chinese). Chin Sci Bull, 2003, 19: 2046-2049 [刘威, 束文圣, 蓝崇钰. 宝山堇菜(Viola baoshanensis)———种新的镉超富集植物. 科学通报, 2003, 19: 2046-2049]

21 Huang H, Pan W B. Uptake and accumulation of Cadmium by hyperaccumulator Euphobia thymifolia L. (in Chinese). In: Proceedings of the 2nd Advanced Seminar on Risk Assessment and Remediation of Heavy Metal Pollution Monitoring, 2008. 64-70 [黄华, 潘伟斌. 超积累植物小飞扬 草(Euphobia thymifolia L.)对Cd的吸收和积累. 第二届重金属污染监测风险评价及修复技术高级研讨会, 2008. 64-70]

22 Wang H, Tang S M, Liao X J, et al. A new manganese-hyperaccumulator: Polygonum hydropiper L. (in Chinese). Ecol Environ, 2007, 16: 830-834 [王华, 唐树梅, 廖香俊, 等. 锰超积累植物——水蓼. 生态环境学报, 2007, 16: 830-834] 
23 Xue S G, Chen Y X, Lin Q, et al. Phytolacca acinosa Roxb. (Phytolaccaceae): A new manganese hyperaccumulator plant from Southern China (in Chinese). Acta Ecol Sin, 2003, 23: 935-937 [薛生国, 陈英旭, 林琦, 等. 中国首次发现的锰超积累植物——商陆. 生态学报, 2003, 23: 935937]

24 Kang W, Zheng J. Ricinus communis, a new copper hyperaccumulator (in Chinese). J Anhui Agric Sci, 2011, 39: 1449-1451, 1466 [康薇, 郑进. 蓠 麻———种新的铜超积累植物. 安徽农业科学, 2011, 39: 1449-1451, 1466]

25 Jiang L Y, Yang X E, Ye Z Q, et al. Uptake, distribution and accumulation of copper in two ecotypes of Elsholtzia. Pedosphere, 2003, 13: 359-366

26 Environment Canada. Management Plan for the Hart's-tongue Fern (Asplenium scolopendrium) in Canada. Species at Risk Act Management Plan Series. Environment Canada, Ottawa, 2013

27 Shao S X, Zheng B S, Su H C, et al. A new species of selenium hyperaccumulator identified in Yutangba Se deposit area (in Chinese). Acta Mineral Sin, 2007, (Z1): 567-570 [邵树勋, 郑宝山, 苏宏灿, 等. 湖北渔塘坝硒矿区发现超富集硒植物. 矿物学报, 2007, (Z1): 567-570]

28 Chaney R L, Angle J S, Broadhurst C L, et al. Improved understanding of hyperaccumulation yields commercial phytoextraction and phytomining technologies. J Environ Qual, 2007, 36: 1429-1443

29 Yang X E, Fu X X, Ni W Z, et al. A new zinc (Zn) hyperaccumulator: Sedum alfreii H. (in Chinese). Chin Sci Bull, 2002, 13: 1003-1006 [杨肖娥, 龙新宪, 倪吾钟, 等. 东南景天 (Sedum alfredii H.) ———种新的锌超积累植物. 科学通报, 2002, 13: 1003-1006]

30 Zhang X H, Luo Y P, Huang H T, et al. Leersia hexandra Swartz: A newly discovered hygrophyte with chromium hyper-accumulator properties (in Chinese). Acta Ecol Sin, 2006, 26: 950-953 [张学洪, 罗亚平, 黄海涛, 等. 一种新发现的湿生铬超积累植物——李氏禾(Leersia hexandra Swartz). 生态学报, 2006, 26: 950-953]

31 Wu Z L, Yin X B, Bañuelos G S, et al. Effect of selenium on control of postharvest gray mold of tomato fruit and the possible mechanisms involved. Front Microbiol, 2016, 6: 1441

32 Silva V M, Boleta E H M, Lanza M G D B, et al. Physiological, biochemical, and ultrastructural characterization of selenium toxicity in cowpea plants. Environ Exp Bot, 2018, 150: 172-182

33 Zhao F J, McGrath S P, Meharg A A. Arsenic as a food chain contaminant: Mechanisms of plant uptake and metabolism and mitigation strategies. Annu Rev Plant Biol, 2010, 61: 535-559

34 Blaby-Haas C E, Merchant S S. Iron sparing and recycling in a compartmentalized cell. Curr Opin Microbiol, 2013, 16: 677-685

35 Yuan L X, Zhang Y. Characterization on R hizosphere bacteria communities from selenium hyperaccumulator Cardamine hupingshanesis (in Chinese). Curr Biotechnol, 2017, 7: 395-401 [袁林喜, 张影. 硒超积累植物壶瓶碎米荠的根际微生物特征研究. 生物技术进展, 2017, 7: 395401]

36 Acuña J J, Jorquera M A, Barra P J, et al. Selenobacteria selected from the rhizosphere as a potential tool for Se biofortification of wheat crops. Biol Fertil Soils, 2013, 49: 175-185

37 Durán P, Acuña J J, Jorquera M A, et al. Enhanced selenium content in wheat grain by co-inoculation of selenobacteria and arbuscular mycorrhizal fungi: A preliminary study as a potential Se biofortification strategy. J Cereal Sci, 2013, 57: 275-280

38 Sharma A, Johri B N, Sharma A K, et al. Plant growth-promoting bacterium Pseudomonas sp. strain GRP3 influences iron acquisition in mung bean (Vigna radiata L. Wilzeck). Soil Biol Biochem, 2003, 35: 887-894

39 Sirohi G, Upadhyay A, Srivastava P S, et al. PGPR mediated zinc biofertilization of soil and its impact on growth and productivity of wheat. J Soil Sci Plant Nut, 2015, 15: 202-216

40 Xiang C G, Wang S R, Yang S J, et al. The biological indication of soil animals to soil environment (in Chinese). Chin Agric Sci Bull, 2007, 23: 364-367 [向昌国, 王圣瑞, 杨世俊, 等. 土壤动物对土壤环境的生物指示作用. 中国农学通报, 2007, 23: 364-367]

41 Bakonyi G, Nagy P, Kádár I. Long-term effects of heavy metals and microelements on nematode assemblage. Toxicol Lett, 2003, 140-141: 391401

42 Weiss B, Larink O. Influence of sewage sludge and heavy metals on nematodes in an arable soil. Biol Fert Soils, 1991, 12: 5-9

43 Wang C Y, Guo S R, Cheng Y J, et al. Effects of exogenous calcium on $\mathrm{K}^{+}, \mathrm{Ca}^{2+}, \mathrm{Mg}^{2+}$ content and ATPase activity in cucumber seedlings under root-zone hypoxic stress (in Chinese). Acta Hortic Sin, 2010, 37: 731-740 [王长义, 郭世荣, 程玉静, 等. 外源钙对根际低氧胁迫下黄瓜植株 钾、钙、镁离子含量和ATPase活性的影响. 园艺学报, 2010, 37: 731-740]

$44 \mathrm{Lu} \mathrm{X} \mathrm{C}$, Chen L, Tian X H, et al. Effects of $\mathrm{CaCO}_{3}$ addition under $\mathrm{Zn}$ supply on wheat seedings growth and $\mathrm{Zn}$ uptake (in Chinese). Chin J Appl Ecol, 2006, 17: 1424-1428 [陆欣春, 陈玲, 田霄鸿, 等. 供锌条件下碳酸钲对小麦幼苗生长和锌吸收的影响. 应用生态学报, 2006, 17: 14241428]

45 Lu Y P, Wang Z M, Yuan L X, et al. Preliminary study on rule of synergetic biofortification and interaction of selenium and iodine (in Chinese). Soils, 2018, 50: 1208-1213 [鲁亚普, 王张民, 袁林喜, 等. 硒碘联合生物营养强化规律及硒碘交互作用初步研究. 土壤, 2018, 50: 1208-1213]

46 Zhang Z, Yuan L, Qi S, et al. The threshold effect between the soil bioavailable molar Se:Cd ratio and the accumulation of Cd in corn (Zea mays L.) from natural Se-Cd rich soils. Sci Total Environ, 2019, 688: 1228-1235

47 Korbas M, O'Donoghue J L, Watson G E, et al. The chemical nature of mercury in human brain following poisoning or environmental exposure. 
ACS Chem Neurosci, 2010, 1: 810-818

48 Ming J J, Yin H Q, Zhu Y F, et al. Effects of selenate stress on the growth and physiological indexes of Cardamine violifolia O. E. Schulz during seedling stage (in Chinese). Curr Biotechnol, 2017, 7: 486-491 [明佳佳, 殷红清, 朱云芬, 等. 硒酸钠胁迫对堇叶碎米荠苗期生长及生理指标的 影响. 生物技术进展, 2017, 7: 486-491]

49 Lu Y P. A study on the preparation of selenium fertilizer coated with polyurethane and evaluation of sustained release of selenium (in Chinese). Master Dissertation. Hefei: University of Science and Technology of China, 2020 [鲁亚普. 聚氨酯包膜硒肥制备与硒元素缓释效果评估研究. 硕士学位论文. 合肥: 中国科学技术大学, 2020]

50 Zhao F J. Long-term experiments at Rothamsted Experimental Station: Introduction and experience (in Chinese). J Nanjing Agric Univ, 2012, 35: 147-153 [赵方杰. 洛桑试验站的长期定位试验: 简介及体会. 南京农业大学学报, 2012, 35: 147-153]

51 Lu X Q, Wang J, Zhu Y Y, et al. Study on Se speciation and bioaccessibility of typical Se-enriched plants (in Chinese). Soils, 2018, 50: 1229-1234 [陆晓奇, 王健, 朱元元, 等. 典型富硒植物中硒形态和生物可给性研究. 土壤, 2018, 50: 1229-1234]

52 Qi H Y, Yang J, Tang L, et al. Changes of mineral contents and retention factors in food materials cooked by different methods (in Chinese). Food Ind, 2016, 37: 21-24 [戚浩或, 杨俊, 汤璐, 等. 不同烹调方法对食材中矿物质保留因子的影响. 食品工业, 2016, 37: 21-24]

53 Hao F L, Liang X, Fan Y, et al. Effects of polyphenol extracts from black soybean seed coat on the activity of $\alpha$-amylase and $\alpha$-glucosidase in vitro (in Chinese). Food Saf Food Qual, 2017, 8: 3359-3364 [郝飞龙, 梁骁, 范芗, 等. 黑豆皮多酚提取物体外对 $\alpha$-淀粉酶和 $\alpha$-葡萄糖苷酶活性的影 响. 食品安全质量检测学报, 2017, 8: 3359-3364]

54 Wang X W, Song L Q, Zong X X. Study on the yogurt mixed with walnut milk and whole milkand the nutrients analysis (in Chinese). J Shanxi Agric Univ (Nat Sci Ed), 2003, 23: 348-350 [王晓闻, 宋丽琴, 宗学醒. 核桃乳-牛乳混合发酵酸奶的研制及成分分析. 山西农业大学学报(自 然科学版), 2003, 23: 348-350]

55 Cheng Y Y. The introduction of reference intake of dietary nutrients for Chinese residents, 2013 revision (in Chinese). Acta Nutr Sin, 2014, 36: 313-317 [程义勇. 《中国居民瞨食营养素参考摄人量》2013修订版简介. 营养学报, 2014, 36: 313-317]

56 Long Z, Yuan L, Hou Y, et al. Spatial variations in soil selenium and residential dietary selenium intake in a selenium-rich county, Shitai, Anhui, China. J Trace Elem Med Biol, 2018, 50: 111-116

57 Huang Y, Wang Q, Gao J, et al. Daily dietary selenium intake in a high selenium area of Enshi, China. Nutrients, 2013, 5: 700-710

58 Gao J, Liu Y, Huang Y, et al. Daily selenium intake in a moderate selenium deficiency area of Suzhou, China. Food Chem, 2011, 126: 1088-1093

59 Sun G X, Van de Wiele T, Alava P, et al. Bioaccessibility of selenium from cooked rice as determined in a simulator of the human intestinal tract (SHIME). J Sci Food Agric, 2017, 97: 3540-3545

$60 \mathrm{Lu}$ X Q. A study on selenium bioavailability and anti-hepatoma function of typical selenium-enriched plants materials (in Chinese). Doctor Dissertation. Hefei: University of Science and Technology of China, 2013 [陆晓奇. 典型富硒植物材料中硒生物有效性及其抗肝癌作用研究. 博士学位论文. 合肥: 中国科学技术大学, 2013]

61 Lyons G, Genc Y, Graham R. Biofortification in the Food Chain and Use of Selenium and Phyto-compounds in Risk-reduction and Control of Prostrate. Boca Raton: CRC Press, 2008

62 Waters D J, Hayden D W, Bell F W, et al. Prostatic intraepithelial neoplasia in dogs with spontaneous prostate cancer. Prostate, 1997, 30: 92-97

63 Lan T. Toenail selenium as an index of selenium intake of middle-aged men in low selenium areas (in Chinese). J Environ Hyg, 1993, (6): 369 [蓝 天. 脚趾甲硒作为低硒地区中年男子硒摄入的指标. 环境卫生学杂志, 1993, (6): 369]

64 Liu Q, Zhao X, Ma J, et al. Selenium (Se) plays a key role in the biological effects of some viruses: Implications for COVID-19. Environ Res, 2021, 196: 110984

65 Zhang J, Taylor E W, Bennett K, et al. Association between regional selenium status and reported outcome of COVID-19 cases in China. Am J Clin Nutr, 2020, 111: 1297-1299

66 Moghaddam A, Heller R A, Sun Q, et al. Selenium deficiency is associated with mortality risk from COVID-19. Nutrients, 2020, 12: 2098

67 Im J H, Je Y S, Baek J, et al. Nutritional status of patients with COVID-19. Int J Infect Dis, 2020, 100: 390-393

68 Yin X B, Wang Z M, Yuan L X, et al. Functional agriculture in China: An 11-year research and practices. In: Bañuelos G, Lin Z Q, Liang D L, et al., eds. Selenium Research for Environment and Human Health: Perspectives, Technologies and Advancements. Boca Raton: CRC Press, 2020. $101-102$

69 Schomburg L, Riese C, Michaelis M, et al. Synthesis and metabolism of thyroid hormones is preferentially maintained in selenium-deficient transgenic mice. Endocrinology, 2006, 147: 1306-1313

70 Liu G, Chen D, Guan W W, et al. A selenium detection equipment with convenient use and protection function (in Chinese). PRC Patent, CN207096249U, 2018-03-13 [刘广, 陈冬, 管文文, 等.一种便于使用并具有保护功能的硒检测设备. 中国专利, CN207096249U, 2018-03-13]

71 China Science Daily. The first new selenium-efficient rapeseed of the world cultivated in China (in Chinese). J Seed Ind Guide, 2019, (12): 32 [中 国科学报. 我国育成全球首个硒高效蔬菜杂交种“硒滋圆1号”. 种业导刊, 2019, (12): 32]

72 Yang Y B, Wang X F, Liu S. High quality and high yield cultication techniques of Xiziyuan No. 1, a new selenium-efficient rapeseed cultivar (in 
Chinese). J Changjiang Veg, 2020, (22): 30-31 [杨艳斌, 王新发, 刘晟. 硒高效油菜莒新品种“硒滋圆1号”优质高产栽培技术. 长江蔬菜, 2020, (22): 30-31]

73 Sun S C, Sun Y, Yuan W Y, et al. Breeding and qualitative analysis for black grain wheat 76 of superi-or quality (in Chinese). Acta Agron Sin, 1999, (1): 50-54 [孙善澄, 孙玉, 袁文业, 等. 优质黑粒小麦76的选育及品质分析. 作物学报, 1999, (1): 50-54]

74 Ren Y K, Niu Y Q, Wang K W, et al. Planting performance and utilization of selenium rich black black grain wheat variety "Donghei No. 1" in Qitai, Xinjiang (in Chinese). Bull Agric Sci Technol, 2018, (12): 258-259 [任永康, 牛瑜琦, 王康武, 等. 富硒黑粒小麦品种冬黑1号在新疆奇台 种植表现及其开发利用. 农业科技通讯, 2018, (12): 258-259]

75 Zhang C Y, Wang L. HarvestPlus in China: Breeding Crops for Better Nutrition Breeding for Better Nutrition (in Chinese). Beijing: China Agricultural Science and Technology Press, 2009 [张春义, 王否. 生物强化在中国: 培育新品种 提供好营养. 北京: 中国农业科学技术出版社, 2009]

76 Agricultural Expo Network. A new sweet potato variety with high $\beta$-carotene solves farmers' health problems (in Chinese). J Changjiang Veg, 2010, (1): 41 [农博网. 高 $\beta$-胡萝卜素甘著新品种解决农民健康问题. 长江蔬菜, 2010, (1): 41]

77 Zhang N, Sun J, Xiong H Z, et al. Breeding and characteristics of Japonica Rice with high resistant starch content and diabetes mellitus (in Chinese). Chin Rice, 2011, 17: 63-65 [张宁, 孙健, 熊海铮, 等. 高抗性淀粉含量糖尿病专用粳稻的选育及其特征特性. 中国稻米, 2011, 17: 6365]

78 Zhang N, Wu D X, Shu X L, et al. A breeding method of Japonica Rice with high resistance starch and high zinc polymerization (in Chinese). PRC Patent, CN106900539A, 2018-08-28 [张宁, 吴殿星, 舒小丽, 等.一种高抗性淀粉和高锌聚合的粳稻选育方法. 中国专利, CN106900539A, 2018-08-28] 


\title{
The review of key scientific issues of functional agriculture and development suggestions for "14th Five-Year Plan"
}

\author{
Xuebin Yin ${ }^{1,2,3,5^{*}}$, Qiguo Zhao ${ }^{1,2,3}$, Yulong Yin ${ }^{6}$, Qingqing Chen ${ }^{2,4}$, Zhangmin Wang ${ }^{2,3}$, Jiaping Song ${ }^{5}$, \\ Xiaoli Wang ${ }^{5}$, Jinyu Lin ${ }^{5}$, Lili Wang ${ }^{7}$, Xiaohang Liu ${ }^{8} \&$ Zezhou Zhang ${ }^{2}$ Ning Zhang ${ }^{2}$ \\ ${ }^{1}$ Key Laboratory of Functional Agriculture, Suzhou Institute for Advanced Research, University of Science and Technology of China, Suzhou 215123, \\ China; \\ ${ }^{2}$ National Innovation Center for Functional Rice, Nanjing 210031, China; \\ ${ }^{3}$ Nanjing Institute for Functional Agriculture Science and Technology (iFAST), Nanjing 210031, China; \\ ${ }^{4}$ College of Life Science and Resources and Environment, Yichun University, Yichun 336000, China; \\ ${ }^{5}$ School of Earth and Space Sciences, University of Science and Technology of China, Hefei 230026, China; \\ ${ }^{6}$ Institute of Subtropical Agriculture, Chinese Academy of Sciences, Changsha 410125, China; \\ ${ }^{7}$ College of Agronomy, Hunan Agricultural University, Changsha 410128, China; \\ ${ }^{8}$ College of Agriculture, Shanxi Agricultural University, Taiyuan 030801, China \\ * Corresponding author, E-mail: xbyin@ustc.edu.cn
}

Functional agriculture is a new concept in the research area of agriculture put forward by academician Zhao Qiguo in 2008, aiming at solving the global problem of "hidden hunger" of human beings. It also represents the new direction and trend of the development of the modern agricultural technology. After 13 years of exploration, the unique discipline system and scientific technical innovation system of functional agriculture have already been formed. In the 669th Xiangshan Science Conference, it was made clear that functional agriculture had achieved a breakthrough from " 0 " to " 1 ". " 0 " represents the earliest period in which functional agriculture is established, and we are now at the stage where considerable achievements of functional agriculture are being made, which is marked as " 1 ". This paper summarizes nine key scientific issues and related research progress in detail, as systematically showed as follows. Through the large-scale investigation of soil functional components and their effects on agricultural products, soil, plants and surface water, the effects of parent material and soil forming process on soil functional substances have beenstudied. Great progress on absorption and transformation of functional substances between soil and crops has been made, such as the establishment of Artificial Root Experimental System (ARE System), assessment methods on bioavailability of functional components and the transformation mechanism of functional components of plants. Several hyperaccumulator plants closely related to functional components and heavy metal were introduced, on the basis of which the mechanism of enrichment is discussed. Besides, the environmental impact assessment of functional components of functional agriculture production is also summarized in this paper. This topic mainly elaborates four subjects: plant protection of functional components, interaction between microorganism and many functional components, interaction among different functional components, and hazard and pollution control technology for functional fertilizers. This article also discusses the progress of studies on morphological variation of functional components of the food during different cooking processes such as fry, stir-fry and boil etc. and that of products processing of functional agriculture. In addition, the effects and mechanisms of functional substances and functional products on human health were introduced, and the studies on the intervention of functional substances and functional products was reviewed. Meanwhile, the latest development of technologies of functional agriculture is also outlined, including new methods, facility and equipment etc., such as rapid detection of functional components and their morphology of food, soil and plants etc., functional animal husbandry, germplasm cultivation, and precise regulation of functional substances. However, functional agriculture is still at the early development stage, and in the scientific and technological innovation system of functional agriculture, there are many tasks to undertake, such as the innovation of research method system, the perfection of technology innovation system, the safety and standardization of products, and the imperfection of industrial system. In order to achieve the above goals, this article finally puts forward to the top-level construction of development strategies of functional agriculture during the "14th Five-Year Plan" period, to promote the realization of the leap from " 1 " to " 100 ".

functional agriculture, hidden hunger, material flow, functional components

doi: 10.1360/TB-2021-0383 